1 Universidade Estadual do Oeste do Paraná (Unioeste) - Cascavel (PR), Brasil. paula.vasconcellos@hotmail. com

\section{Condições da exposição a agrotóxicos de portadores da doença de Parkinson acompanhados no ambulatório de neurologia de um hospital universitário e a percepção da relação da exposição com o adoecimento}

\author{
Pesticide exposure conditions on Parkinson's disease patients followed \\ at a neurology clinic of a university hospital and perception of the \\ relationship of exposure with illness
}

Paula Renata Olegini Vasconcellos', Maria Lucia Frizon Rizzotto', Gicelle Galvan Machineski $\mathbf{1}$ Rose Meire Costa1

DOI: $10.1590 / 0103-1104201912308$

RESUMO O objetivo desta pesquisa foi investigar, a partir da história laboral de portadores da doença de Parkinson acompanhados no ambulatório de neurologia de um hospital universitário, a ocorrência e as condições da exposição a agrotóxicos, bem como a percepção da relação da exposição com o adoecimento. Trata-se de estudo exploratório e descritivo, com abordagem quantitativa e qualitativa, realizado no Hospital Universitário do Oeste do Paraná, em Cascavel, Paraná, Brasil. Foram entrevistados 32 sujeitos, o usuário ou familiares, com doença de Parkinson, por meio de entrevista telefônica a partir de roteiro semiestruturado. Desses, 16 (50\%) eram homens; a maioria idosos aposentados (87,48\%), com baixa escolaridade (53,13\%); 25 (78,11\%) trabalharam na agricultura, residindo na área rural de 11 anos a 30 anos; 24 (74,98\%) afirmaram ter tido contato com agrotóxicos de forma direta ou indireta; a forma mais citada de aplicação dos agrotóxicos foi com pulverizador costal; a maioria (75\%) não utilizou equipamentos de proteção individual e aprendeu a manipular os agrotóxicos com familiares. Conclui-se que um número expressivo de indivíduos com doença de Parkinson teve alguma atividade laboral na agricultura durante a vida, muitos deles com contato direto com agrotóxicos, seja no preparo e aplicação ou mesmo na lavagem das roupas.

PALAVRAS-CHAVE Agroquímicos. Doença de Parkinson. Exposição ocupacional. Saúde pública.

ABSTRACT The objective of this research was to investigate, from the work history of patients with Parkinson's disease, followed at the neurology outpatient clinic of a university hospital, the occurrence and conditions of exposure to pesticides, as well as the perception of the relationship between exposure and illness. This is an exploratory and descriptive study with a quantitative and qualitative approach, carried out at the Hospital Universitário do Oeste do Paraná, in Cascavel, Paraná, Brazil. Thirty-two subjects, the user or family members, with Parkinson's disease were interviewed by telephone interview using a semi-structured script. Of these, 16 (50\%) were men; most of them retired elderly (87.48\%), with low education (53.13\%); 25 (78.11\%) worked in agriculture, living in rural areas from 11 to 30 years old; 24 (74.98\%) stated that they had direct or indirect contact with pesticides; the most cited form of pesticide application was with costal spray; Most (75\%) did not use personal protective equipment and learned to handle pesticides with family members. It is concluded that a significant number of individuals with Parkinson's disease had some labor activity in agriculture during life, many of them with direct contact with pesticides, either in the preparation and application or even in the washing of clothes.

KEYWORDS Pesticides. Parkinson's disease. Occupational exposure. Public health. 


\section{Introdução}

Após a Segunda Guerra Mundial, observou-se o que se conhece como 'revolução verde' ou revolução agrícola contemporânea, inicialmente nos países centrais, mas, a partir da década de 1950, em países em desenvolvimento com grandes dimensões territoriais como o Brasil, a Índia e o México. Essa 'revolução', cujo discurso ideológico era para combater a fome do mundo, promoveu um processo de elevada mecanização do campo, seleção de plantas com forte potencial de rentabilidade e vasta utilização de fertilizantes, modificando o processo clássico de produção agrícola para aumentar a produção, em especial, de arroz, milho, trigo e soja para exportação. Com isso, cresceu o uso extensivo de agrotóxicos para controlar os deficit de produção causados pelas doenças agrícolas e aumentar a produtividade'.

No Brasil, isso se inicia na década de 1960 , com apoio do governo, visando aumentar a produtividade, modernizar a agricultura, facilitar as atividades no campo com o uso de máquinas (tratores, colheitadeiras), produtos químicos (fertilizantes e agrotóxicos) e sementes modificadas, vendidos por multinacionais que entraram no País. Como desdobramento desse processo de modernização, formaram-se os latifúndios e a produção de monoculturas principalmente nas regiões Centro-Oeste, Sul e Sudeste2,3.

Desde 2008, o Brasil vem ocupando posição de destaque mundial no consumo de agrotóxicos paralelamente à divulgação de estudos que revelam seus impactos negativos na saúde humana. A capacidade de dispersão e de transformação dos agrotóxicos no meio ambiente favorece sua mobilidade em vários ecossistemas com alcance de amplos territórios, expondo distintos grupos populacionais aos seus efeitos tóxicos, como trabalhadores de diversas atividades vinculadas à produção e ao consumo, moradores que residem próximos de fábricas de agrotóxicos e fazendas, além da ingestão de alimentos contaminados. Esses impactos são relacionados com o atual modelo de desenvolvimento, focado na produção de commodities para exportação $0^{4,5}$.
Os efeitos adversos da exposição aos agrotóxicos dependem das características químicas, da quantidade absorvida ou ingerida, do tempo de exposição e das condições gerais de saúde da pessoa exposta, sendo divididos em agudos e crônicos ${ }^{6-8}$. Os efeitos agudos aparecem logo após o contato do trabalhador com o agrotóxico e em até 24 horas, apresentando características definidas. Os efeitos crônicos são percebidos em questão de semanas, meses ou anos após o contato com esses produtos, o que dificulta a associação desse fenômeno com o desenvolvimento de patologias como aquelas que afetam o Sistema Nervoso Central (SNC) e o Sistema Nervoso Periférico (SNP). Isso porque as causas também podem se relacionar a fatores genéticos, ambientais, alimentares, imunológicos, entre outros ${ }^{8-10}$.

Além disso, os danos associados à saúde dos trabalhadores rurais vêm sendo mascarados pelo discurso da relevância do aumento da produtividade, já que os efeitos dos agrotóxicos na saúde humana, em especial os crônicos, não têm sido identificados de forma adequada ${ }^{10,11}$.

Entre as patologias que acometem o SNC, há a Doença de Parkinson (DP), descrita pela primeira vez em 1817, em Londres, pelo médico britânico James Parkinson 12. É uma doença neurológica, que afeta os movimentos do indivíduo, dando origem a tremores associados à lentidão de movimentos (bradicinesia), à rigidez muscular e à instabilidade postural ${ }^{13}$.

A DP ocorre devido à degeneração da substância negra do tronco encefálico, que sintetiza a dopamina, neurotransmissor que tem como função transmitir a informação na forma de sinais elétricos de um neurônio para outro. A redução dos níveis de dopamina gera o desequilíbrio dos sistemas envolvidos no controle dos movimentos ${ }^{13-15}$.

A doença é considerada de origem multicausal, sendo que, atualmente, pondera-se a relação da exposição a agrotóxicos associada ao aumento do risco de DP em todo o mundo, principalmente entre aqueles que relatam um trabalho agrícola, como observado por Rugbjerg et al. ${ }^{16}$ em estudo realizado no Canadá; Tüchsen 
e Astrup ${ }^{17}$, na Dinamarca; e Liew et al. ${ }^{18}$, nos Estados Unidos da América (EUA).

A associação da DP à exposição laboral a agrotóxicos já está confirmada e oficializada na França. O governo francês, após analisar inúmeros relatórios científicos, acrescentou ao Decreto $^{\circ}{ }^{2012-665}$, de 4 de maio de 2012, a DP como uma doença de trabalhadores agrícolas que utilizaram agrotóxicos em suas lavouras ${ }^{19,20}$.

Ainda são poucos os estudos brasileiros que dimensionam as doenças crônicas e avaliam os efeitos decorrentes do uso de agrotóxicos na saúde humana. Além disso, ainda existem poucas pesquisas que discutem os modelos agrícolas em disputa, como a agricultura familiar, a agroecologia em contraposição ao modelo de uso intensivo de agrotóxicos no Brasil9-11,21.

Pesquisas que analisam as consequências da exposição prolongada a agrotóxicos podem e devem ultrapassar a abordagem quantitativa, necessitando também considerar a narrativa dos indivíduos envolvidos no processo de trabalho agrícola. Os estudos qualitativos são importantes para auxiliar a descoberta de novos elementos sobre o problema levantado, que, muitas vezes, ficam invisibilizados em determinados tipos de desenhos de pesquisa, pouco contribuindo para o debate sobre o uso de agrotóxicos no País e para a formulação de políticas públicas ${ }^{\mathbf{1 0}}$.

Assim, o objetivo da pesquisa foi investigar, a partir da história laboral de portadores da DP acompanhados no ambulatório de neurologia do Hospital Universitário do Oeste do Paraná (Huop), a ocorrência e as condições da exposição a agrotóxicos, bem como a percepção da relação da exposição com o adoecimento.

\section{Material e métodos}

Pesquisa exploratória, descritiva, de abordagem quantitativa e qualitativa, desenvolvida com pacientes com DP e/ou familiares atendidos no ambulatório de neurologia do Huop. A partir de pesquisa nos prontuários do referido serviço, foram identificados 48 usuários diagnosticados com DP, dos quais 32 (66,66\%) foram incluídos no estudo por atender aos critérios de inclusão, ou seja, ter diagnóstico de DP realizado por neurologista; ser maior de 18 anos, ter frequentado o serviço, pelo menos uma vez, nos últimos 5 anos e aceitar fazer parte da pesquisa.

A coleta de informações foi realizada de março a maio de 2018 por meio de Entrevista Telefônica Assistida por Computador (Etac) a partir de um formulário baseado no Protocolo de Avaliação das Intoxicações Crônicas por Agrotóxicos ${ }^{22}$, sendo adaptado para a DP; validado por cinco juízes com conhecimentos na área dessa doença ou de agrotóxicos; e realizado teste-piloto para ajustes finais. A entrevista foi realizada com os que aceitaram participar da pesquisa, o Termo de Consentimento Livre e Esclarecido (TCLE) foi substituído por consentimento verbal, cuja concordância se deu por meio de gravação após apresentação dos objetivos da pesquisa e leitura do termo. As entrevistas foram gravadas e transcritas na íntegra e utilizadas para complementar os dados quantitativos. Cada entrevistado foi identificado pela letra E, seguido de um número a partir da digitação no banco dados.

O projeto foi aprovado pelo Comitê de Ética em Pesquisa com seres humanos da Universidade Estadual do Oeste do Paraná (Unioeste) sob parecer n. 2.414.998 de 2017, e foram respeitados os aspectos éticos conforme Resolução no ${ }^{0}$ 466/2012 CNS ${ }^{23}$.

\section{Resultados e discussão}

Entre os participantes, 50\% (16) eram do gênero masculino, sendo 87,48\% (28) com mais de 60 anos; 81,24\% (26) estavam aposentados, 87,48\% (28) residiam em área urbana; $43,74 \%$ (14) possuíam menos de 4 anos de estudo e 9,39\% (03) afirmaram ser analfabetos.

Santana et al. ${ }^{\mathbf{2 4}}$ relataram em seu estudo com agricultores que $55,3 \%$ tinham um baixo nível de escolaridade e que $24,5 \%$ eram analfabetos, sendo que $64 \%$ faziam uso de agrotóxicos. O 
baixo nível de escolaridade pode dificultar a leitura e o entendimento sobre os efeitos nocivos dos agrotóxicos, porém não pode ser considerado como fator isolado para o seu uso incorreto.

Ao serem questionados sobre a leitura do rótulo da embalagem dos agrotóxicos, entre os participantes que tiveram contato direto, apenas um afirmou que sempre lia os rótulos. Os demais não sabiam ler ou aprenderam com familiares como utilizar o produto, um afirmou que sequer sabia se tinha rótulo "Mas eu nem lembro se tinha rótulo... depois de um tempo começou vir outros... é... diziam que era veneno, mas daí já tinha se envenenado"(E15).

Ao serem questionados sobre as possíveis causas para o desenvolvimento da DP, a maioria (59,35\%) não soube identificar nenhum aspecto e/ou determinante para a DP, como expresso na fala de um entrevistado "[...] não faço nem ideia. Assim, na verdade eu também nem cheguei a perguntar para o médico o que que causa essa doença do Parkinson né" (E5).

Sete entrevistados afirmaram acreditar que aspectos emocionais, como nervosismo (E23), estresse (E30) ou mesmo alcoolismo estariam relacionados com as possíveis causas da doença: "Ele era alcoolista, olha pelo que eu li, a gente, é uma possibilidade, embora eu não sei as causas que pode ocorrer o Parkinson" (E17).

Na literatura, o risco para a DP está associado a fatores como: exposição a agrotóxicos, consumo de produtos lácteos, história de melanoma e lesão traumática no cérebro ${ }^{25}$.

O trabalho rural foi citado por um entrevistado como possível causador:

A mãe foi muito esforçada na roça, foi muito judiada na roça né? A mãe fazia todos os trabalhos pesados, até grávida, ia na roça com nós! Grávida de nós e ela ia trabalhar na roça! (E7).

Pelo menos dois entrevistados associaram a DP à exposição a agrotóxicos, um como suspeita:

[...] a gente por ser criança e adolescente pode ter tido algum contato, mas assim trabalhar com ele, lidar direto com o veneno não. A gente sentia o cheiro, mas era normal, não tinha como evitar. (E10).

E outro de forma mais direta:

... andei trabalhando com veneno agrícola um certo tempo [...] sim hoje falam que tem gente que trabalhou muito tempo com inseticida e contraiu Parkinson. (E15).

Dardiotis et al. ${ }^{\mathbf{2 6}}$, por meio de uma revisão de literatura, evidenciaram vários estudos que investigaram a associação entre fatores genéticos, exposição a agrotóxicos e o surgimento da DP. Foram encontrados resultados em que a perda neuronal pode predispor ao desenvolvimento da doença, assim, é importante considerar essas interações para compreender melhor o mecanismo patogênico da DP. Estudos conduzidos por Fitzmaurice et al. ${ }^{27}$ revelaram que a exposição ambiental ao agrotóxico benomil, fungicida usado no Brasil, interfere na atividade metabólica da enzima Aldeído Desidrogenase (ALDH); e como resultado, a toxina Dopal (3-4-Dihidroxifenilacetaldeido), naturalmente produzida pelo cérebro, acumula-se e causa danos aos neurônios dopaminérgicos, o que aumenta os riscos da DP. Os autores discutem ainda que mesmo com o envolvimento genético da DP, os fatores ambientais são relevantes na sua origem.

Pavlou e Outeiro 28 afirmam que a modulação epigenética da expressão gênica por fatores ambientais, que provocam mudanças na expressão ou função gênica sem alterações na sequência do DNA (Ácido Desoxirribonucleico), está surgindo como um mecanismo importante na DP. Concluem que a DP pode ser causada pela combinação de mutações genéticas, toxinas ambientais e disfunção mitocondrial, e a modificação epigenética atua como mediadora entre exposição ambiental e genes, contribuindo para a neurodegeneração relacionada com a DP.

Em relação à atividade laboral exercida pelos sujeitos da pesquisa durante a vida, $78,11 \%$ (25) trabalharam na agricultura e 
residiram na área rural por um tempo médio de 11 anos a 30 anos, em vários estados da federação (Minas Gerais, Paraná, Pernambuco, Rio Grande do Sul, Rondônia, Santa Catarina e São Paulo). Três participantes residiram a vida toda na área rural:

Olha, ele sempre trabalhou na agricultura né. Sempre fez parte da agricultura. Desde criança. Ainda depois que se aposentou ele continuou trabalhando. (E5).

Algumas mulheres afirmaram ter trabalhado na lavoura e nos cuidados domésticos a vida toda (E7, E8, E9).

Revisão realizada por Mostafalou e Abdollahi29 sobre a exposição humana a agrotóxicos e sua toxicidade, com análise de riscos para desenvolver a DP, encontrou que a exposição laboral a agrotóxicos aumenta o risco de desenvolver a doença de 1,3 vez a 5,6 vezes.

Entre os participantes, 74,98\% (24) afirmaram ter contato direto ou indireto com agrotóxico. A fala que segue expõe uma rotina de exposição muito comum no campo até os dias atuais:

Trabalhou no meio de agrotóxico! Até eu me intoxiquei com isso, o pai passou veneno no algodão e botou nós pra trabalhar no meio, eu fui parar no hospital! [...] Ele [o pai] aplicava o veneno e a gente já estava ali na roça, né? O algodão ia muito veneno! Você acredita que até hoje ele aplica veneno, e não pode né? Porque ele já teve câncer na boca, e ainda ele passa perto de casa [...] e o cheiro vem tudo dentro de casa! (E7).

Dados obtidos em região agrícola nos EUA revelaram que a exposição por longo tempo, desde a infância, aumenta de quatro vezes a seis vezes o risco de desenvolver a DP na vida adulta ${ }^{30}$.

Estudo realizado na França - incluindo homens trabalhadores agrícolas com casos de DP clinicamente identificadas -, que utilizou questionário ocupacional com indicadores como duração, exposição cumulativa e intensidade, encontrou que a exposição de alta intensidade a agrotóxicos foi positivamente associada à DP, como também a exposição aos agrotóxicos em fazendas especializadas em vinhedos foi associada à $\mathrm{DP}^{\mathbf{3} 1}$.

A utilização dos agrotóxicos, para eliminação de vetores como o da malária, nos serviços públicos ainda é uma prática comum no Brasil, expondo ao produto tanto a população no geral quanto os agentes que aplicam

[...] ela morou muitos anos em Rondônia e lá na época que ela entrou lá, tinha muita malária, então a Sucam [Superintendência de Campanhas de Saúde Pública] passava assim a cada 15/20 dias, um mês, borrifando tudo. As casas, as fazendas, tudo [...] nas paredes das casas era meio 'branquicenta' de tanto passar aquilo [...] os meninos que trabalhavam na Sucam carregavam aquele tambor nas costas, não era como hoje que tem o caminhão, era tudo manual. (E16).

O DDT (Diclorodifeniltricloroetano) é um tipo de inseticida organoclorado que foi amplamente utilizado no Brasil nas campanhas sanitárias para o combate do mosquito do gênero Anopheles, transmissor da malária. A aplicação do agrotóxico ocorria dentro dos domicílios para acabar com focos de transmissão da doença. Por se tratar de um organoclorado neurotóxico agudo e crônico para o homem, pode ocasionar mudanças de comportamento e distúrbios de equilíbrio ${ }^{32}$.

O uso desse agrotóxico nas lavouras foi banido em 1985; e em 1998, foi proibido para o uso nas campanhas sanitárias. Contudo, apenas em 2009, com a Lei ${ }^{\circ} 11.936$, de 14 de maio de 2009, sua comercialização para qualquer fim foi proibida no País ${ }^{33,34}$.

Alguns participantes relataram a exposição ambiental, pela percepção do cheiro que ficava no ar após a aplicação do agrotóxico.

[...] a gente sentia o cheiro, mas era normal, não tinha como evitar [...]. (E10).

[...] teve uma época que ele arrendou bastante, 
mas como ele tinha uma casinha bem lá no meio para ficar cuidando de tudo né, então ele ficava perto, ele ficava o dia todo nessa casa. (E14).

[...] a casa ficava no meio da roça, daí a gente sentia o cheiro né? Aquele cheiro de longe, por mais que fechava as portas e as janelas vinha aquele cheiro ainda [...]. (E27).

Costello et al. ${ }^{30}$ concluíram que a aplicação de dois tipos de agrotóxicos (maneb e paraquat), em uma distância de 500 metros de residências na Califórnia, aumentou exponencialmente o risco de desenvolver a DP, demonstrando os efeitos da exposição indireta ao agrotóxico.

A relação de atividades desenvolvidas na agricultura e o Parkinson foi objeto de estudo na França, no qual foi possível observar que a incidência da doença aumentou com a maior proporção de terras que eram dedicadas à agricultura, destacando-se a produção de vinhas. Essa associação também foi confirmada em indivíduos não agricultores, mas que moravam em áreas rurais ${ }^{35}$. Da mesma forma, estudos conduzidos por neurologistas da Universidade da Califórnia, Los Angeles, EUA, apresentaram evidências da associação entre DP e agrotóxicos, que expõem não somente o trabalhador rural como também trabalhadores e indivíduos nas proximidades das áreas agrícolas ou que inalaram suas partículas da deriva ${ }^{36}$.

Entre os participantes que afirmaram ter contato com o agrotóxico, de forma direta ou indireta, a maneira de aplicação do produto mais relatada foi a utilização de pulverizador costal por $45,84 \%$ (11) dos sujeitos.

Ele aplicava com aquelas maquininhas manuais, que coloca nas costas, daí no algodão ia um veneno em pó também [...] ele aplicava naquela máquina e subia aquela fumaceira... daí ele passava e aquilo ficava no ar. (E7).

A preocupação com a saúde devido à aplicação de agrotóxico por meio da pulverização foi relatada no estudo de Conceição et al.37.
Os agricultores que manipulavam o produto disseram que, com a pulverização, ficavam mais expostos; e a direção do vento também tornava maior a exposição e o contato com o agrotóxico.

É importante também destacar a contaminação ambiental pela pulverização, a dispersão de agrotóxicos pelo vento ou água no meio ambiente, ou seja, a ‘deriva técnica'. O agrotóxico não atinge somente a lavoura na qual foi aplicado, pois também acaba sendo disseminado pelo ar e o seu entorno com pelo menos 30\% do produto, podendo ultrapassar até $70 \%$, mesmo seguindo todas as orientações e normas técnicas de aplicação. Isso indica que não existe a utilização de agrotóxicos sem contaminar o ambiente, como também sem afetar a saúde dos trabalhadores ou moradores da área rural ${ }^{\mathbf{3 8}}$.

No que se refere ao uso do Equipamento de Proteção Individual (EPI), dos indivíduos que relataram contato direto na aplicação do agrotóxico, 75\% (9) disseram não usar nenhuma peça do EPI.

$O$ veneno vinha em pó, a gente pegava em um balde e ia jogando ele com a mão, direto com a mão. Passava sem máscara, sem nada, sem luva, sem nenhuma proteção, sem nenhuma orientação, era veneno e veneno, e... diziam que não era perigoso. (E15).

No caso desses indivíduos, em sua grande maioria, o contato com os agrotóxicos ocorreu nas décadas de 1970 e 1980, quando a regulamentação praticamente não existia. A Norma Regulamentadora (NR) 6, primeira que trata do uso de EPI, ocorreu em 1978, o que dificultava o acesso às informações e às recomendações do seu uso ${ }^{39}$.

No entanto, a recomendação do emprego de EPI, na maioria das vezes, é ineficaz, tanto por não utilizar todos os itens necessários para a atividade laboral em questão como pela opção de não usar, dado o desconforto que os equipamentos causam, como excesso de calor, atrapalhando o processo de trabalho. Também já se sabe que os EPI não protegem totalmente o trabalhador, podendo muitas vezes virar meio de contaminação $\mathbf{3 7 , 4 0 , 4 1}^{\mathbf{3}}$. 
Nenhuma participante, que também muitas vezes já estavam expostas devido a atividades na lavoura e contaminação ambiental, relatou o uso de EPI para a lavagem de roupas utilizadas na aplicação do agrotóxico. Essa atividade é considerada uma ação de contato direto de exposição ao agrotóxico pela NR $31^{\mathbf{4 2}}$.

Abreu e Alonzo ${ }^{\mathbf{4 3}}$ apontam em sua revisão sobre o trabalho rural e riscos à saúde que, muitas vezes, as roupas que foram usadas na aplicação dos agrotóxicos são manipuladas no mesmo tanque que outras roupas dos indivíduos da família; ou até mesmo feita, nesse local, a higienização dos equipamentos utilizados para aplicação do agrotóxico.

Os participantes relataram que, no contato indireto com o agrotóxico, em grande parte dos casos, a aplicação do produto era realizada pelos pais ou pelos cônjuges, sendo que estes, em vários relatos, não faziam a leitura dos rótulos das embalagens, pois aprendiam a utilizar com outros familiares ou vizinhos

[...] eu lembro assim que ele perguntava né, os vizinhos também falavam: estou passando isso, rende tantos litros o vidrinho. Informação assim de vizinhos, lá onde comprava também, na veterinária assim, mas ele não era de ler rótulo não. (E16).

No estudo de Santana et al. ${ }^{24}$, os agricultores que afirmaram trabalhar com agrotóxicos relataram que as informações sobre o uso do produto, em $44,2 \%$, eram obtidas por meio dos vizinhos, como também por meio de televisão e rádio. Uma parcela disse que recebeu orientações de profissionais, porém, 18,6\% nunca tiveram nenhum tipo de informação de como utilizar corretamente o agrotóxico.

Alguns entrevistados relataram o plantio de fumo, cultura que usa bastante agrotóxicos, como forma de sustento da família (E7, E16, E18, E30). "[...] lá no município que a gente morava pra gente conseguir dinheiro era fumo. É que nem hoje a soja, naquela época lá era o fumo" (E18). O uso de agrotóxico nas fumiculturas é intenso; e, em geral, o trabalho é realizado manualmente.
[...] trabalhava com fumo daí eles falavam que tinha que botar veneno senão enchia de bicho lá, e como era de estufa tem que selecionar folha por folha para botar secar no galpão. Então eles manuseavam esse fumo quando tirava da roça, tinha que secar assim na sombra, tinham contato o dia inteiro com isso. (E16).

[...] tinha contato com o veneno, porque a gente plantava fumo. [...] A gente lá plantava tudo que comia. Mas o veneno era só no fumo que a gente vendia para fazer dinheiro. Naquela época a gente não precisava passar veneno [nos alimentos]. Só no fumo porque os bichinhos roíam. (E18).

Estudo de Murakami et al. ${ }^{44}$ com fumicultores em pequenas propriedades rurais no Paraná demonstra a baixa escolaridade e a precariedade de saneamento e saúde, além da alta exposição a agentes tóxicos causando alterações psiquiátricas, perda auditiva e polineuropatia tardia induzida por organofosforados.

A região Sul reúne maior concentração da produção de fumo do País, sendo cultivado geralmente por famílias em pequenas propriedades rurais ${ }^{45}$. O cultivo do fumo, segundo Pignati et al. ${ }^{\mathbf{4 6}}$, teve a maior quantidade de agrotóxicos utilizados por hectares no Brasil nos últimos anos.

Atualmente, como alternativa para corrigir os efeitos danosos ao ecossistema do modelo de agricultura convencional, tem sido proposto o modelo de agroecologia como forma de reduzir os impactos ambientais e de gerar novas formas de desenvolvimento rural sustentável. Busca a interação de conhecimentos, técnicas e práticas respeitando as condições ecológicas, econômicas, técnicas e culturais de cada região e população. Por meio deste, pode-se criar um equilíbrio ecológico em todo o mundo garantindo a segurança alimentar. Ao primar pela biodiversidade, a agroecologia mantém um equilíbrio ecológico global, garantindo a segurança alimentar ${ }^{47,48}$.

Devido ao longo período passado entre a exposição aos agrotóxicos e o momento da entrevista, muitos participantes não lembravam 
o nome dos agrotóxicos utilizados, caracterizando um viés de memória.

É importante ressaltar que, como a DP tem um início tardio, os agrotóxicos que tiveram intensa utilização no passado podem não ser mais utilizados e comercializados hoje em dia, sendo importante a realização de estudos adicionais com agrotóxicos mais recentes ${ }^{20}$.

Considera-se relevante avaliar as populações rurais expostas a agrotóxicos no que se refere ao diagnóstico de DP, uma vez que este acontece anos após os primeiros sintomas da doença, sendo de grande valia estudos sobre fatores de riscos ambientais. Assim, a exposição a agrotóxicos em baixas dosagens por longos períodos deve se constituir em alerta para os serviços de saúde e para a sociedade, visando reduzir as consequências para as futuras gerações.

\section{Conclusões}

A maioria dos entrevistados com diagnóstico de DP teve alguma atividade laboral na agricultura durante a vida; morou na área rural em média entre 11 anos e 30 anos, teve contato com agrotóxicos, quer seja no preparo e aplicação ou mesmo na lavagem de roupas contaminadas.

Merece destaque o pouco conhecimento da toxicidade do produto bem como o manuseio incorreto e a pouca adesão ao uso de EPI, devido à maioria dos indivíduos ser idosa e, na época do contato com o agrotóxico, não ter acesso a informações. Identificou-se também a baixa percepção referente à associação da
DP com a exposição a agrotóxicos, apesar de grande parte dos entrevistados referir exposição prolongada a vários tipos de agrotóxicos e do fato de, há alguns anos, essa relação ter sido reconhecida em países europeus.

Assim, sabendo que a associação dos fatores genéticos e ambientais pode desencadear a DP, e que o aparecimento dos sintomas ocorre tardiamente após a origem dessa doença, é de extrema importância realizar estudos para avaliar os fatores ambientais, em especial na população rural.

De tal modo, investigações adicionais sobre esse fator de risco por meio da interação de várias áreas de conhecimento nos contextos socioculturais, político-econômicos e ambientais, e com outras possibilidades metodológicas, contribuirão para a reflexão e para a implementação de práticas de prevenção da DP nas futuras gerações, com ações avaliativas e controle dos efeitos nocivos dos agrotóxicos.

Dessa forma, as produções científicas podem fornecer dados relevantes para chamar a atenção dos gestores e profissionais do SUS para a temática visando promover novas práticas e políticas de saúde.

\section{Colaboradores}

Vasconcellos PRO (0000-0003-0984-1458)*e Rizzotto MLF (0000-0003-3152-1362)* contribuíram em todas as etapas deste estudo. Machineski GG (0000-0002-8084-921X)* e Costa RM (0000-0002-5344-5076)* contribuíram na correção e elaboração final do estudo. 


\section{Referências}

1. Mazoyer M, Roudart L. Histórias das agriculturas no mundo: do neolítico à crise contemporânea [internet]. São Paulo: Unesp; Nead; 2010. [acesso em 2017 jun 13]. Disponível em: http://www.ufrgs.br/pgdr/publicacoes/producaotextual/lovois-de-andrade-miguel-1/ mazoyer-m-roudart-l-historia-das-agriculturas-no-mundo-do-neolitico-a-crise-contemporanea-brasilia-nead-mda-sao-paulo-editora-unesp-2010-568-p-il.

2. Agra NG, Santos RF. Agricultura brasileira: situação atual e perspectivas de desenvolvimento [internet]. In: Anais do XXXIX Congresso da Sociedade brasileira de Economia e Sociologia Rural; 2001 Ago 5-8; Recife. Recife: Mar Hotel; 2001. p. 1-9. [acesso em 2018 jul 9]. Disponível em: http://www.gp.usp.br/ files/denru_agribrasil.pdf.

3. Souza GS, Costa LCA, Maciel AC, et al. Presença de agrotóxicos na atmosfera e risco à saúde humana: uma discussão para a Vigilância em Saúde Ambiental. Ciênc. Saúde Colet. 2017; 22(10):3269-3280.

4. Carneiro FF, Pignati W, Rigotto RM, et al., organizadores. Dossiê ABRASCO - Um alerta sobre os impactos dos agrotóxicos na saúde. Parte 1 - Agrotóxicos, Segurança Alimentar e Nutricional e Saúde. Rio de Janeiro: Abrasco; 2012

5. Veiga MM, Silva DM, Veiga LBE, et al. Análise da contaminação dos sistemas hídricos por agrotóxicos numa pequena comunidade rural do Sudeste do Brasil. Cad. Saúde Pública. 2006; 22(11):2391-2399.

6. Organização Pan-americana da Saúde; Organização Mundial de Saúde. Manual de Vigilância da saúde de populações expostas a agrotóxicos. Brasília, DF: OPAS; OMS; 1996. [acesso em 2017 abr 13]. Disponível em: http://bvsms.saude.gov.br/bvs/publicacoes/ livro2.pdf.

7. Peres F, Moreira JC. Agrotóxicos, saúde e ambiente: uma introdução ao tema. É veneno ou é remédio? Agrotóxicos, saúde e ambiente [internet]. Rio de Janeiro: Fiocruz; 2003. p. 21-41. [acesso em 2017 ago 20]. Disponível em: http://books.scielo.org/id/ sg3mt/pdf/peres-9788575413173.pdf.

8. Rigotto RM, Aguiar ACP. Invisibilidade ou invisibilização dos efeitos crônicos dos agrotóxicos à saúde? Desafios à ciência e às políticas públicas. In: Nogueira RP, Santana JP, Rodrigues VA, et al., organizadores. Observatório Internacional de Capacidades Humanas, Desenvolvimento e Políticas Públicas: estudos e análises 2. Brasília, DF: UnB; ObservaRH; Nesp; Fiocruz; Nethis; 2015. p. 47-90.

9. Carneiro FF, Augusto LGS, Rigotto RM, et al. Dossiê ABRASCO: um alerta sobre os impactos dos agrotóxicos na saúde. Rio de Janeiro: Expressão Popular; 2015.

10. Porto MF, Soares WL. Modelo de desenvolvimento, agrotóxicos e saúde: um panorama da realidade agrícola brasileira e propostas para uma agenda de pesquisa inovadora. Rev. bras. saúde ocup. 2012; 37(125):17-50

11. Lopes CVA, Albuquerque GSC. Agrotóxicos e seus impactos na saúde humana e ambiental: uma revisão sistemática. Saúde debate. 2018; 42(117):518-534.

12. Parkinson J. An Essay on the Shaking Palsy. J. Neuropsychiatry Clin Neurosci. 2002; 14(2):223-236.

13. Goldman L, Ausiello D. Cecil Medicina. 23. ed. Rio de Janeiro: Elsevier; 2009. v. 2, Traduzido.

14. Luz KPS, Coronago VMMO. A Doença de Parkinson na Pessoa Idosa e a Relação com sua Qualidade de Vida. Id on Line Rev. Psic. 2017; 11(35):116-136.

15. Pivetta M. A fraqueza das células-tronco. Pesquisa Fapesp. 2011; (183):18-21.

16. Rugbjerg K, Harris MA, Shen H, et al. Pesticide exposure and risk of Parkinson's disease - a population-based case-control study evaluating the potential for recall bias. Scand. j. work environ. health. 2011; 37(5):427-436. 
17. Tüchsen F, Astrup JA. Agricultural work and the risk of Parkinson's disease in Denmark, 1981-1993. Scand. j. work environ. health. 2000; 26(4):359-362.

18. Liew Z, Wang A, Bronstein J, et al. Job Exposure Matrix (JEM) derived estimates of life-time occupational pesticide exposure and the risk of Parkinson's Disease. Arch. environ. occup. health. 2014; 69(4):241-251.

19. França. Decreto $n^{\circ}$ 2012-665, de 4 de maio de 2012 [internet]. Revê e complementa as tabelas de doenças ocupacionais na agricultura anexadas ao livro VII do código da pesca rural e marítima. Jornal Oficial da República Francesa. 2012 Maio 4. [acesso em 2017 set 3]. Disponível em: http://www.legifrance. gouv.fr/affichTexte.do;jsessionid=F02B64383C21B 5FF75E0565AE7309CB6.tpdjol7v_1? cidTexte=JOR FTEXT000025804441\&categ orieLien=id.

20. Elbaz A, Moisan F. The scientific bases to consider Parkinson's disease an occupational disease in agriculture professionals exposed to pesticides in France. J. epidemiol. community health. 2016; (70):319321.

21. Dutra LS, Ferreira AP. Associação entre malformações congênitas e a utilização de agrotóxicos em monoculturas no Paraná, Brasil. Saúde debate. 2017; 41(esp2):241-253.

22. Paraná. Secretaria de Estado da Saúde do Paraná. Superintendência de Vigilância em Saúde Centro Estadual de Saúde do Trabalhador. Protocolo de avaliação das intoxicações crônicas por agrotóxicos. Curitiba: SESP; 2013. [acesso em 2017 ago 20]. Disponível em: http://www.saude.pr.gov.br/arquivos/File/CEST/ Protocolo_AvaliacaoIntoxicacaoAgrotoxicos.pdf.

23. Brasil. Ministério da saúde. Resolução no 466, de 12 de dezembro de 2012 [internet]. incorpora, sob a ótica do indivíduo e das coletividades, referenciais da bioética, tais como, autonomia, não maleficência, beneficência, justiça e equidade, dentre outros, e visa a assegurar os direitos e deveres que dizem respeito aos participantes da pesquisa, à comunidade científica e ao Estado. Diário Oficial da União. 13 Dez
2012. [acesso em 2018 ago 18]. Disponível em: https://bvsms.saude.gov.br/bvs/saudelegis/cns/2013/ res0466_12_12_2012.html.

24. Santana CM, Costa AR, Nunes RMP, et al. Exposição ocupacional de trabalhadores rurais a agrotóxicos. Cad. Saúde Colet. 2016; 24(3):301-307.

25. Campdelacreu J. Parkinson's disease and Alzheimer disease: environmental risk factors. Neurología. 2014; 29(9):541-549.

26. Dardiotis E, Xiromerisioua G, Hadjichristodoulou C, et al. The interplay between environmental and genetic factors in Parkinson's disease susceptibility: The evidence for pesticides. Toxicology. 2013; (307):17-23.

27. Fitzmaurice AG, Rhodes SL, Lulla A, et al. Aldehyde dehydrogenase inhibition as a pathogenic mechanism in Parkinson disease. Proc. Natl. Acad. Sci. U.S.A. 2013; 110(2):636-641.

28. Pavlou MAS, Outeiro TF. Epigenetics in Parkinson's Disease. Adv. exp. med. biol. 2017; (918):363-390.

29. Mostafalou S, Abdollahi M. Pesticides: an update of human exposure and toxicity. Arch. toxicol. 2017; 91(2):549-599.

30. Costello S, Cockburn M, Bronstein J, et al. Parkinson's Disease and Residential Exposure to Maneb and Paraquat From Agricultural Applications in the Central Valley of California. Am. j. epidemiol. 2009; 169(8):919-926.

31. Moisan F, Spinosi J, Delabre L, et al. Association of Parkinson's Disease and Its Subtypes with Agricultural Pesticide Exposures in Men: A Case - Control Study in France. Environ. health perspect. 2015; 123(11):1123-1129.

32. D'amato C, Torres JPM, Malm O. DDT (dicloro difenil tricloroetano): toxicidade e contaminação ambiental- uma revisão. Qim. nova. 2002; 25(6):995-1002.

33. Fundação Oswaldo Cruz, Escola Nacional de Saú- 
de Pública Sergio Arouca. Lei suspende uso do DDT no Brasil. 26 Maio 2009. [acesso em 2018 out 10]. Disponível em: http://www6.ensp.fiocruz.br/ visa/?q=node/4009.

34. Brasil. Lei $\mathrm{n}^{\circ} 11.936$ de 14 de maio de 2009 [internet]. Proíbe a fabricação, a importação, a exportação, a manutenção em estoque, a comercialização e o uso de diclorodifeniltricloretano (DDT) e dá outras providências. Diário Oficial da União. 14 Maio 2009. [acesso em 2018 out 10]. Disponível em: http://www. planalto.gov.br/ccivil_03/_Ato2007-2010/2009/Lei/ L11936.htm

35. Kab S, Spinosi J, Chaperon L, et al. Agricultural activities and the incidence of Parkinson's disease in the general French population. Eur. j. epidemiol. 2017; 32(3):203-216.

36. Wang A, Costello S, Cockburn M, et al. Parkinson's disease risk from ambient exposure to pesticides. Eur. j. epidemiol. 2011; 26(7):547-555.

37. Conceição MH, Jonas MF, Albuquerque OMR. Relatos da percepção do agricultor de Brazlândia-DF sobre o uso de agrotóxicos. Participação. 2015; (29):5563.

38. Londres F. Agrotóxicos no Brasil um guia para ação em defesa da vida. Rio de Janeiro: AS-PTA - Assessoria e Serviços a Projetos em Agricultura Alternativa; 2011.

39. Brasil. Ministério do Trabalho e Emprego. NR 06equipamento de proteção individual, 1978. [acesso em 2018 set 1]. Disponível em: https://enit.trabalho. gov.br/portal/images/Arquivos_SST/SST_NR/NR06.pdf.

40. Veiga MM, Duarte FJCM, Meirelles LA, et al. A contaminação por agrotóxicos e os Equipamentos de Pro- teção Individual (EPIs). Rev. bras. saúde ocup. 2007;

32(116):57-68.

41. Meirelles LA, Veiga MM, Duarte F. A contaminação por agrotóxicos e o uso de EPI: análise de aspectos legais e de projeto. Laboreal. 2016; 12(2):75-82.

42. Brasil. Ministério do Trabalho e Emprego. Portaria nº 86 de 03 de março de 2005. NR 31 - segurança e saúde no trabalho na agricultura, pecuária silvicultura, exploração florestal e aquicultura. Dário Oficial da União. 4 Mar 2005.

43. Abreu PHB, Alonzo HGA. Trabalho rural e riscos à saúde: uma revisão sobre o "uso seguro" de agrotóxicos no Brasil. Ciênc. Saúde Colet. 2014; 19(10):41974208.

44. Murakami Y, Pinto NF, Albuquerque GSC, et al. Intoxicação crônica por agrotóxicos em fumicultores. Saúde debate. 2017; 41(113):563-576.

45. Biolchi MA, Bonato AA, Oliveira MA. A cadeia produtiva do fumo. Contexto Rural. 2003; 3(4):5-55.

46. Pignati WA, Lima FANS, De Lara SS, et al. Distribuição espacial do uso de agrotóxicos no Brasil: uma ferramenta para a Vigilância em Saúde. Ciênc. Saúde Colet. 2017; 22(10):3281-3293.

47. Czymmeck A. Agroecologia - manejo de "pragas" e doenças. Fortaleza: Fundação Konrad Adenauer; 2010. v. 6.

48. Leff E. Agroecologia e saber ambiental. Agroecol. e Desenv. Rur. Susten. 2002; 3(1):36-51.

Recebido em 21/04/2019

Aprovado em 01/10/2019

Conflito de interesse: inexistente

Suporte financeiro: não houve 